\title{
Doom, gloom, or boom? Perceptions of climate change among Canadian winegrowers
}

This article was published in the following Dove Press journal: International Journal of Wine Research

\section{Emilie Jobin-Poirier Gary Pickering ${ }^{1-4}$ Ryan Plummer ${ }^{1,4,5}$}

'Environmental Sustainability Research Centre, Brock University, St. Catharines, Ontario, Canada; ${ }^{2}$ Department of Biological Sciences and Psychology, Brock University, St. Catharines, Ontario, Canada; ${ }^{3} \mathrm{Cool}$ Climate Oenology and Viticulture Institute, Brock University, St. Catharines, Ontario, Canada; ${ }^{4}$ Sustainability Research Centre, The University of the Sunshine Coast, Sippy Downs, Queensland, Australia; ${ }^{5}$ Stockholm Resilience Centre, Stockholm University, Stockholm, Sweden

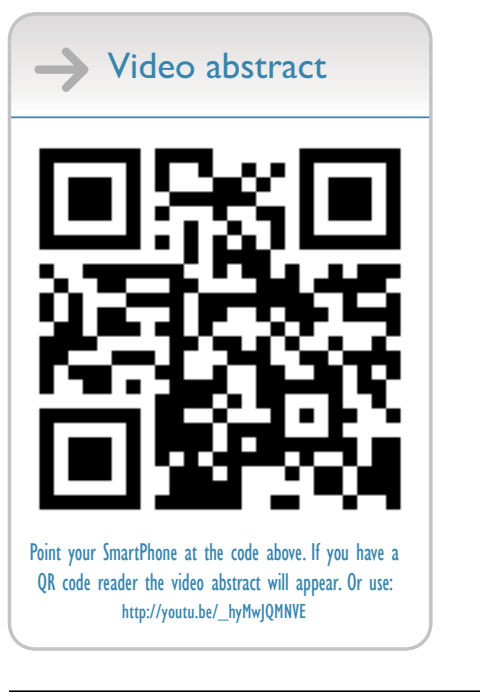

Correspondence: Gary Pickering Department of Biological Sciences, Brock University, 1812 Sir Isaac Brock Way, St. Catharines, Ontario L2S 3AI Canada $\mathrm{Tel}+\mathrm{I} 9056885550$ ext $47 \mid 5$

Fax +19056881855

Email gpickering@brocku.ca
Background: Climate change (CC) could have both positive and negative consequences for the Canadian and global wine industries. Understanding how winegrowers perceive $\mathrm{CC}$, however, can provide insight into how to better assist the industry to cope with the impacts of a changing climate.

Material and methods: An online survey of 122 Canadian winegrowers was conducted to understand knowledge, beliefs, environmental values, and perceptions towards $\mathrm{CC}$ and its impact on the Canadian wine industry. Environmental values (New Environmental Paradigm score), subjective and objective CC knowledge, $\mathrm{CC}$ skepticism and uncertainty, belief in anthropogenic $\mathrm{CC}$, and perceptions of the impacts of CC were measured using established tools.

Results: Overall, results show that Canadian winegrowers have a relatively low level of CC skepticism, a medium level of CC scientific knowledge, a pro-ecological (as opposed to anthropological) worldview, and generally believe that $\mathrm{CC}$ is caused by a mix of anthropogenic and natural forces. Moreover, a majority of respondents $(60 \%)$ believe that $\mathrm{CC}$ has both positive and negative consequences on their vineyard and winery operations, while $8 \%$ think that climate change has no consequence on their operations. An extended growing season for grapes, the improvement of grape and wine quality, and the possibility to grow varieties that are not currently viable were the main beneficial consequences of CC reported by participants, while an increase in both disease and pests in the vineyard were the most commonly identified disadvantages. Finally, no association was observed between CC skepticism, knowledge, environmental values, and the perception of CC consequences. Conclusion: Our findings inform communication strategies for the wine industry around CC, and provide important baseline information on winegrowers' perceptions that inform wider efforts to improve the capacity of the industry to develop and adapt to the consequences of CC

Keywords: wine, grapes, sustainability, adaptation

\section{Introduction}

Global climate change (CC) poses a major threat to our society and puts ecosystems and humankind at risk. From the warming of temperatures to the occurrence of extreme weather events, the repercussions of $\mathrm{CC}$ on human systems are increasingly difficult to ignore, especially in sectors such as agriculture, in which climate variations are experienced on a daily basis. ${ }^{1}$ The wine industry is one of the agricultural sectors that could be most impacted by $\mathrm{CC}$. In fact, since a precise climate range is required to produce quality wines, short-term and long-term climate variability put grapevines at a higher risk than other crops. ${ }^{2,3}$ In the international wine industry, a need to understand, assess, and be able to adapt to the effects of $\mathrm{CC}$ on grape and wine production is of broad and current interest. ${ }^{4-6}$ However, effectively addressing $\mathrm{CC}$ is a complex endeavor 
that requires a transdisciplinary approach involving a myriad of stakeholders. ${ }^{7}$ In Canada, winegrowers (winemakers/ grape-growers) are at the forefront of decision making in the wine industry. As such, their perceptions are very likely to influence the relationship between $\mathrm{CC}$ manifestations and vineyard and winery practices.

Previous literature has demonstrated that perceptions can give insight into people's comprehension of $\mathrm{CC}$ and their responses to the phenomenon. ${ }^{8}$ Understanding CC perceptions could also reveal the most salient barriers that prevent the adoption of best practices and inform how to effectively communicate $\mathrm{CC}$ information. ${ }^{9,10}$ Therefore, understanding how winegrowers perceive $\mathrm{CC}$ should be part of the strategy to help the industry manage the issue.

A multitude of psychological factors and barriers can shape perceptions and can either encourage or obstruct the adoption of solutions that would improve environmental sustainability. ${ }^{11}$ Prior research has shown that perceptions of $\mathrm{CC}$, its impacts, and the participation of individuals in pro-environmental actions are influenced by existing values, beliefs, and knowledge. For instance, pro-environmental values have been positively associated with pro-environmental behavior in a number of studies ${ }^{12-14}$ and a higher likelihood to endorse pro-environmental public policies. ${ }^{12,14}$ Similarly, $\mathrm{CC}$ knowledge is a crucial component influencing $\mathrm{CC}$ perceptions and behavior. According to the Knowledge Deficit Model, the general public lacks an expert's understanding of a phenomenon, which explains why they do not respond to it like scientific experts would. ${ }^{15}$ People with low scientific CC knowledge would therefore be less likely to support CC policies, be concerned about the issue, and appropriately address it. ${ }^{16}$ Hence, determining $\mathrm{CC}$ knowledge among winegrowers should inform how to better communicate $\mathrm{CC}$ information. Also, CC skepticism and uncertainty represent obstacles to mitigation efforts and willingness to adopt climate protection measures. ${ }^{8,17,18}$ For example, while CC awareness has been increasing internationally in the last few decades, ${ }^{8}$ attribution skeptics - or people who believe that the Earth's climate is changing, but doubt the influence of anthropogenic activities on $\mathrm{CC}^{18}$ - still represent a significant segment of the population, despite the extraordinary scientific consensus regarding its reality. ${ }^{8,19}$ Therefore, assessing individuals' environmental values, CC knowledge, and beliefs is important to understanding their perception and response - or lack thereof - to CC. ${ }^{8}$

Generating over $\$ 9$ billion in national economic impact per year, ${ }^{20}$ the Canadian wine industry (CWI) is booming and increasingly gaining international recognition. ${ }^{21}$ During the last 40 years, Canada has transformed from a marginal grower of native American grapes to a quality producer of acclaimed icewines and world-class table wines. ${ }^{22}$ Most Canadian wine regions are found in four main provinces: Ontario accounts for $\sim 48 \%$ of the national economic impact of the CWI, British Columbia 31\%, Québec 12\%, and Nova Scotia $0.2 \% .{ }^{20}$ Across the country, wine-producing areas are generally considered "cool-climate" due to their relatively short growing seasons and their cold winters. ${ }^{23,24}$ However, as the second largest country on Earth, Canada is home to a range of climates and topographies, which makes Canadian wines very diverse.

In the past few decades, the gradual shift toward warmer temperatures has allowed the ripening of cool climate Vitis Vinifera varieties in Canada, especially in Ontario and British Columbia. ${ }^{25}$ For Canadian wine regions, this could bring both opportunities and losses in the future. A longer growing season, including an extended frost-free period, coupled with a rise in temperature during ripening, could help growers plant commercially successful, less cold-tolerant grapevines. This could also allow for the development of new wine styles and wine regions, which were previously not suited to quality grape growing. ${ }^{24,26}$ Conversely, changing temperatures could also lessen the capacity of established wine regions to produce the cool-suited cultivars that currently thrive in those areas. ${ }^{24,27}$ Similarly, icewine production could be compromised by the rise of temperatures created by $\mathrm{CC}$. Icewine is a unique dessert wine made by pressing frozen grapes that have to be harvested and processed at $-8^{\circ} \mathrm{C}$, or below. Therefore, warmer winter temperatures could lower the number of days available for icewine harvest. ${ }^{28}$

Additionally, $\mathrm{CC}$ is altering precipitation patterns, ${ }^{29,30}$ which could directly impact winegrowing in Canada. ${ }^{24} \mathrm{~A}$ sufficient amount of rainfall is required to ensure grapevines' growth and survival, but high rainfall is associated with lower quality, especially early in the season and close to harvest. In early spring, intense rainfalls can cause an increased pest pressure in vineyards and can thus negatively affect bloom. During the growing season, rainfall can delay ripening and interfere with the optimal berry maturation. During grape ripening, high rainfalls can cause the berries to swell, which dilutes their sugar and flavor and may result in berry splitting, fungal disease, and increased disease pressure. ${ }^{31}$

Moreover, extreme weather events related to $\mathrm{CC}$ are hard to predict and can severely damage crops..$^{24,27,29}$ For instance, temperatures over $30^{\circ} \mathrm{C}$ can alter grapevines' photosynthetic capacity and thus lessen their performance and health, ${ }^{32}$ while cold snaps during the winter can kill or deeply damage 
grapevines. ${ }^{26,27}$ Also, episodes of drought can impact many vital aspects of viticulture and can reduce yield, vine vigor, and ultimately reduce grapevines' potential for survival. ${ }^{27}$

In the international wine industry, little is known about $\mathrm{CC}$ perceptions. In Europe, Alonso and $\mathrm{O}^{\prime} \mathrm{Neill}^{33}$ found that Spanish winegrowers who identified the impacts of $\mathrm{CC}$ were more inclined to adjust their operations than those who did not acknowledged the consequences of CC. Also, research in both Europe ${ }^{34}$ and Canada (Ontario) ${ }^{27}$ observed that perceptions of the impact of $\mathrm{CC}$ - both positive and negative - were linked with winegrowers' interest in adaptation.

In light of these considerations, this study seeks to describe Canadian winegrowers with respect to their environmental values, and CC beliefs and knowledge, as well as their perception of the consequences of $\mathrm{CC}$ on their winery and vineyards' operations. This information captures the "state of the industry" regarding CC perceptions and allows a comparison between provinces, groups of workers, and other populations. In addition, this study seeks to determine how the perceptions of CC impacts vary with values, beliefs, and knowledge. This information should reveal opportunities for knowledge transfer between stakeholders in the industry and inform policymaking to help the industry thrive within the context of CC.

\section{Material and methods \\ Recruitment of participants}

Data were collected from July 2017 until January 2018, using an online bilingual survey hosted on the Qualtrics ${ }^{\circledR}$ platform. To reach as many participants as possible, winegrowers associations of British Columbia, Ontario, Québec, and Nova Scotia were contacted and asked to share the invitation with their members through e-mail or their associations' newsletters. Approximately 1,860 winegrowers were sent a one-page invitation letter that stated the aim of the study as well as the inclusion criteria that participants needed to 1) be working in Canada as a winemaker, grape-grower, or winery owner and 2) be of 18 years or older to participate. To access the survey, a secure URL address was included in the letter. Upon the completion of the survey, participants were eligible to enter a lottery for a $\$ 500$ cash prize. The study has received ethics clearance through the Brock University Research Ethics Board (File \#16-310).

\section{Variables measured}

The survey text is presented in Supplementary material S1. Demographics of the participants were collected including gender, age, and the education level. Characteristics specific to the vineyard or winery operated by participants were also documented, including the role of the respondent in the vineyard or winery (grape-grower, winemaker, owner, employee, or external consultant) and province of production.

A six-item New Environmental Paradigm scale (NEP) ${ }^{12}$ adapted by Whitmarsh ${ }^{10}$ was used to measure environmental values (Supplementary material S2). On a 5-point Likert scale, winegrowers were asked to rate their level of agreement with the statements. Responses were coded with numerical values (1-5), and reverse coding was applied, when necessary. Individual NEP scores were then generated, where higher scores reflect greater pro-environmental values.

$\mathrm{CC}$ belief, as a variable, was deconstructed into two subvariables for consideration. First, uncertainty and skepticism were measured using five attitudes statements adapted from Whitmarsh ${ }^{10}$ and Spence et al. ${ }^{35}$ Using a 5-point Likert scale, participants were asked to rate their level of agreements with the statements. The responses to statements were coded numerically, reverse coding was applied when necessary, and then numbers were averaged to generate uncertainty and skepticism scores. Scores closer to "1" suggest a lower level of skepticism, while scores closer to " 5 " reflect a higher level of CC uncertainty and skepticism. Second, the same question Morris and Pickering ${ }^{36}$ asked to measure belief in anthropogenic $\mathrm{CC}$ was used. Participants were asked to select the circle they think represents the cause(s) of CC. Response options were illustrated as pie charts presenting five different proportions of anthropogenic vs natural causes of CC.

Perceived and assessed knowledge of $\mathrm{CC}$ were both determined. Perceived knowledge was measured by asking participants to guage how much they know about CC by moving a slider on a horizontal line with two anchor phrases positioned at its extremes. I know very little was positioned under the rating of " 1 " at the left end of the line, and I know a great deal was positioned under " 10 " at the right end. ${ }^{36}$ The perceived knowledge average scores were then transformed to percentage values for comparison with the assessed knowledge values. Assessed CC knowledge was measured using Stoutenborough and Vedlitz's ${ }^{16}$ index, which is composed of a set of six true-or-false type questions based on material extracted from the Intergovernmental Panel on Climate Change ${ }^{19}$ and developed with climate scientists. Instead of being presented as a binary question, the additional choice to select the answer I do not know was provided in this study to prevent participants from guessing. An assessed knowledge score was created following a two-step method adapted from Liu et al. ${ }^{37}$ First, the responses to the questions were coded using a $0 / 1$ score $(1=$ correct; $0=$ incorrect and 
I do not know). Second, the six answers were averaged and transformed into a value representing the percentage of correct responses, with $0 \%$ representing no correct responses and $100 \%$ representing all correct responses.

Participants were asked if the consequences of $\mathrm{CC}$ on their operations were mostly positive, mostly negative, positive and negative, or neutral (no consequence). Except for those who selected the latter choice, participants were then directed to a check-all-that-apply multiple-choice question with an open-ended option, which asked them what they perceive to be the major benefits and disadvantages from $\mathrm{CC}$ for the wine industry in their region. Participants who selected mostly positive or positive and negative were asked about the benefits, while those who selected mostly negative and positive and negative were asked about the disadvantages.

The specific benefits and disadvantages chosen for this question were based on Pickering et $\mathrm{al}^{27}$ and from other literature on the commonly discussed effects of $\mathrm{CC}$ on the CWI. ${ }^{24-26,38-40}$ They represent direct impacts of weather events associated with $\mathrm{CC}$ on grape and wine production, with the exception of extended growing season, which is commonly referred to as a positive effect. ${ }^{24-27,39}$ Since Canadian wine regions are mostly considered to be cool climate, low temperatures are certainly recognized as one of the main problems for viticulture and winemaking. ${ }^{38}$ Therefore, the potential benefits used in the multiple-choice question were all related to the predicted increase of annual temperatures. However, the warming of temperatures can also be a drawback for the industry, especially for regions that are currently successful with reliable production of cool-climate varieties and styles, which is reflected in the multiple-choice question. ${ }^{24}$ While the effects of CC can vary from one region to another, the benefits and disadvantages listed are relatively general and not region specific given the desire to survey a wide geographical distribution of the CWI. Finally, to capture as comprehensive a listing as possible of the perceived consequences of $\mathrm{CC}$, an open-ended option allowed participants to list any other benefit(s) or disadvantage(s) they identified as important.

\section{Data treatment and analysis: general approach}

XLSTAT Version 2017.19.05.46974 (Addinsoft, NY, USA) was used to perform all data analysis. To assess potential differences in average NEP and skepticism scores between the provinces of Ontario, British Columbia, and Québec, and between categories of respondents (grape-growers, winemakers, and winemakers/grape-growers), one-way ANOVAs, followed by Tukey's $\mathrm{HSD}_{0.05}$ tests, were performed. Nova Scotian participants were excluded from the provincial comparisons because of the low number of respondents from this province $(\mathrm{n}=9)$. Two-sample $t$-test $(\alpha=0.05)$ was conducted to compare owners' and nonowners' NEP and skepticism scores. A Shapiro-Wilk test for normality and a Levene's test for homogeneity were previously performed for each sample compared in the study. Cronbach's $\alpha$ was used to measure the internal consistency of the NEP and skepticism scales (Cronbach's $\alpha>0.7$ demonstrated the reliability of the scales). Since the assessed CC knowledge distributions of participants did not follow normal distributions, knowledge scores were grouped into two categories - low and high - based on the median score of $50 \%$ correct. Contingency tables and chi-squared tests of independence were then used to examine the potential relationships between knowledge and the different categories of workers and their province of work.

To investigate how ecological values, skepticism, and assessed knowledge relate to participants' perceptions of the impacts of $\mathrm{CC}$, contingency tables were created, and chisquared test of independence was performed. The nonparametric Fisher's exact test results were reported in instances where the $P$-value of the chi-squared tests of independence was very close to significance. To improve statistical power, NEP, skepticism and uncertainty, and assessed knowledge scores were grouped into two categories - low and high - to create contingency tables. NEP scores from 1 to 3.99 were grouped in the low category and scores from 4 to 5 in the high category. The median score of 2.20 was used to categorize the skepticism and uncertainty scores: results $<2.20$ were characterized as low, and scores $\geq 2.20$ were considered high. The median value of $50 \%$ correct responses was used to categorize the assessed knowledge scores. The perceived consequences of CC were classified into three of the four original categories of responses: 1) mostly positive, 2) mostly negative, and 3) positive and negative. Due to the low number of respondents $(n=10)$ who selected the response neutral (no consequence) to the perception of impact question, this was removed from the analysis. The detailed categories of responses for each variable are given in Supplementary material S3.

\section{Results}

\section{Description of participants}

A total of 122 winegrowers completed the survey, which represents an approximate response rate of $6.5 \%$. Participants who did not respond to all questions were excluded from the analysis, excepted for one participant who omitted to respond to $8 \%$ of the demographic questions. At the time they took the survey, $38 \%$ of respondents were working in 
Ontario, 33\% in British Columbia, 22\% in Québec, and 7\% in Nova Scotia. A majority of respondents are male (73\%), aged between 31 and 60 years (77\%), attended University $(81 \%)$, and have worked in the wine industry for $>5$ years $(89 \%)$. The sample is described in detail in Table 1 below.

\section{Environmental values, beliefs, and knowledge}

A NEP score of 3 is commonly considered as the cut-off for an anthropocentric worldview $(<3)$ and a pro-ecological worldview $(>3) .{ }^{41}$ At the national level, the average NEP score was $3.84(\mathrm{SD}=0.66)$, which suggests that Canadian winegrowers have a more ecological than an anthropocentric worldview. The ANOVAs performed did not show a significant difference in NEP scores between provinces $(F=2.03$; $P=0.14)$ or between winemakers, grape-growers, and winemakers/grape-growers $(F=1.63 ; P=0.20)$. Similarly, the $t$-test did not show a significant difference between owners and

Table I Sample description

\begin{tabular}{|l|l|}
\hline Variable measured & $\begin{array}{l}\text { Proportion of } \\
\text { respondents }\end{array}$ \\
\hline Gender & \\
Female & $27 \%$ \\
Male & $73 \%$ \\
Age, years & \\
I8-30 & $5 \%$ \\
$3 I-40$ & $27 \%$ \\
$4 I-50$ & $25 \%$ \\
$5 I-60$ & $25 \%$ \\
Over 60 & $18 \%$ \\
Highest level of education & \\
No formal qualification & $1 \%$ \\
High school diploma & $4 \%$ \\
Apprenticeship or trades certificate or & $4 \%$ \\
diploma & \\
College, CÉGEP, or other nonuniversity & $10 \%$ \\
certificate or diploma & \\
University certificate, diploma, or degree & $12 \%$ \\
below the bachelor level & \\
University certificate, diploma, or degree at \\
the bachelor level & $45 \%$ \\
University graduate degree & \\
Role in the winery/vineyard & \\
Winemaker & $24 \%$ \\
Grape-grower & \\
Winemaker/grape-grower & $61 \%$ \\
Owner & $66 \%$ \\
External consultant & $39 \%$ \\
Years of work experience in the wine industry & $56 \%$ \\
$<5$ years & $4 \%$ \\
II-20 years & $11 \%$ \\
Over 20 years & $26 \%$ \\
\hline
\end{tabular}

nonowners $(t(120)=1.58, P=0.12)$ (Table 2$)$. The shortened (6-item) NEP scale used to measure environmental values was found to be internally consistent (Cronbach's $\alpha=0.71$ ).

At the national level, the average uncertainty and skepticism score was 2.19 ( $\mathrm{SD}=0.73$ ). The average uncertainty and skepticism score is significantly lower in individuals identified as winemakers/grape-growers than in those who work as grape-growers only $(F=4.60, P=0.01)$. No significant difference was observed between provinces $(F=0.80$, $P=0.45)$ or between owners and nonowners $(t(120)=1.12$, $P=0.267$ ) (Table 2). Total agreement and mean scores for the five skepticism statements are presented in Supplementary material S6. The lowest agreement was for The seriousness of climate change is exaggerated, followed by I am uncertain that climate change is really happening and The media is too alarmist about climate change. Approximately half of the participants agreed with the statement It is uncertain what the effects of climate change will be. The highest agreement was for Most scientists agree that climate change is really happening. A reliability analysis was conducted on the five statements, which showed internal consistency (Cronbach's $\alpha=0.73)$. Moreover, the majority of respondents $(78 \%)$ believe $\mathrm{CC}$ is caused by a mix of natural and anthropogenic factors, while only $3 \%$ of respondents believe it is entirely caused by natural forces, and $19 \%$ attribute CC to human activities solely (see Supplementary material S7 for full details).

The assessed knowledge score was measured in terms of the percentage of correct responses. Perceived knowledge was measured on a 10-point scale (1-10) and converted into a percentage value for comparison purposes with the assessed knowledge values. At the national level, the assessed knowledge mean score is $55.3 \%(\mathrm{SD}=21.8)$, while the perceived knowledge mean score is $7.0(\mathrm{SD}=1.8)$, corresponding to $61.7 \%(\mathrm{SD}=23.0)$, which is higher than the assessed knowledge national value. A similar trend is observed for the different groups of workers and for Ontario and British Columbia, whereas in Québec, the assessed knowledge score is slightly higher than the perceived knowledge score (Supplementary materials S4 and S5).

Chi-squared test of independence was performed on contingency tables to examine the potential relationships between the level of assessed CC knowledge (low or high) and the role of the respondents in the winery (winemaker only, grapegrower/winemaker, and grape-grower), their ownership status (owner or nonowner), and their provinces of work (Ontario, British Columbia, or Québec). The tests showed that the level of knowledge is independent from participants' professional role in the winery $\left(\chi^{2}(2, \mathrm{~N}=108)=0.367, P=0.83\right)$, from the 
Table 2 Average responses, for environmental values, climate change skepticism/uncertainty and assessed climate change knowledge for winegrowing provinces and categories of workers

\begin{tabular}{|c|c|c|c|c|c|c|c|c|c|}
\hline \multirow[t]{2}{*}{ Province and worker category } & \multicolumn{3}{|c|}{ NEP scores } & \multicolumn{3}{|c|}{$\begin{array}{l}\text { Uncertainty and } \\
\text { skepticism scores }\end{array}$} & \multicolumn{3}{|c|}{$\begin{array}{l}\text { Assessed knowledge } \\
\text { (\% of correct responses) }\end{array}$} \\
\hline & Average & SD & Sig & Average & SD & Sig & Average & SD & Sig \\
\hline \multicolumn{10}{|l|}{ Provinces $^{\mathrm{a}}$} \\
\hline Ontario $(n=46)$ & 3.8 & 0.8 & NS & 2.3 & 0.9 & NS & 55.4 & 22.3 & NS \\
\hline British Columbia $(n=40)$ & 3.8 & 0.6 & NS & 2.3 & 0.7 & NS & 52.9 & 24.6 & NS \\
\hline Québec $(n=27)$ & 4.1 & 0.5 & NS & 2.1 & 0.6 & NS & 58.0 & 15.3 & NS \\
\hline \multicolumn{10}{|l|}{ Role in the winery/vineyard ${ }^{a}$} \\
\hline Winemakers $(n=28)$ & 4.0 & 0.6 & NS & 2.2 & 0.7 & NS & 59.5 & 18.6 & NS \\
\hline Grape-growers $(n=33)$ & 3.7 & 0.8 & NS & 2.4 & 0.8 & Sig & 51.0 & 25.3 & NS \\
\hline Winemakers/grape-growers $(n=47)$ & 3.9 & 0.7 & NS & 1.9 & 0.7 & Sig & 54.3 & 22.4 & NS \\
\hline \multicolumn{10}{|l|}{ Owners/nonowners ${ }^{b}$} \\
\hline Owners $(n=68)$ & 3.8 & 0.7 & NS & 2.6 & 0.7 & NS & 54.7 & 21.9 & NS \\
\hline Nonowners $(n=54)$ & 3.9 & 0.6 & NS & 2.1 & 0.8 & NS & 56.2 & 21.6 & NS \\
\hline
\end{tabular}

Notes: aOne-way ANOVA was performed, followed by Tukey's HSD test with a $\mathrm{Cl}$ of $95 \%$. ${ }^{\mathrm{T}} \mathrm{Two}$-sample $t$-test was performed, with a $\mathrm{Cl}$ of $95 \%$.

Abbreviations: NEP, new ecological paradigm; NS, nonsignificant; Sig, significant.

ownership status $\left(\chi^{2}(2, \mathrm{~N}=122)=1.04, P=0.31\right)$, and from their province of work $\left(\chi^{2}(2, \mathrm{~N}=113)=1.48, P=0.48\right)$.

\section{Perceived positive and negative consequences of climate change}

As shown in Figure 1, the majority of Canadian winegrowers indicated that the consequences of $\mathrm{CC}$ on their operation are both positive and negative, an equal proportion of them stated that $\mathrm{CC}$ has mostly negative or mostly positive impacts, and a small proportion affirmed that $\mathrm{CC}$ has no impact on their operations. Similar to the national values, the majority of respondents in each province and in each group of workers indicated that the consequences of $\mathrm{CC}$ are positive and negative, while a small portion of respondents perceive the consequences of $\mathrm{CC}$ to be neutral for the wine industry. The perceptions of $\mathrm{CC}$ consequences on the industry for the different categories of winegrowers are given in Supplementary material S8.

The selected benefits and disadvantages of $\mathrm{CC}$ for the CWI are illustrated in Figures 2 and 3, respectively. Other positive and negative consequences of $\mathrm{CC}$ described by respondents are presented in Supplementary material S9. The most frequently cited responses in this "other" category include the uncertainty in predicting the weather, the inconsistent quality, and the variability of yield.

\section{Relationships between values, skepticism, knowledge, and perception of impacts}

The contingency table $\chi^{2}$ result indicates no association between environmental values (NEP scores) and the perception of $\mathrm{CC}$ for the wine industry $\left(\chi^{2}(2, \mathrm{~N}=112)=5.70, P=0.058\right)$.

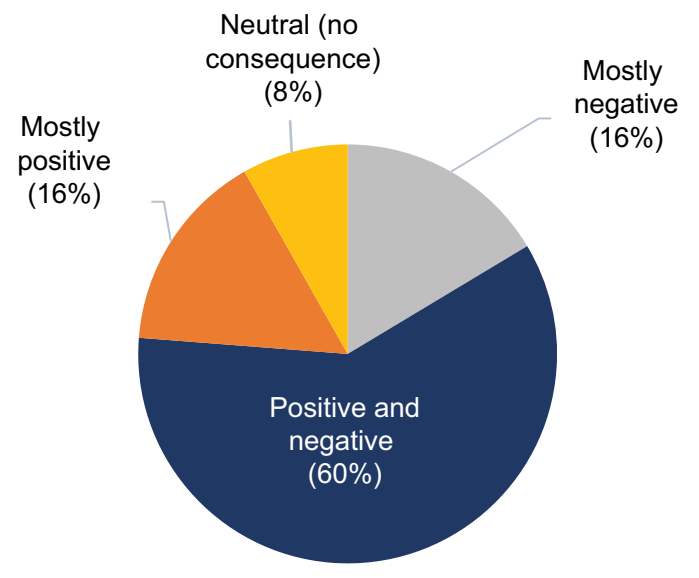

Figure I Consequences of climate change perceived by Canadian winegrowers.

However, the Fisher's exact test indicates that respondents with a more anthropocentric worldview (low NEP scores) see $\mathrm{CC}$ as being mostly positive, while respondents with a more ecological worldview (high NEP scores) were less likely to see CC as being mostly positive for the CWI. Similarly, no association between the level of skepticism and the perception of CC consequences was observed $\left(\chi^{2}(2, \mathrm{~N}=112)=2.25\right.$, $P=0.32)$, nor between level of assessed knowledge and the perception of CC consequences $\left(\chi^{2}(2, \mathrm{~N}=112)=1.82, P=0.40\right)$.

\section{Discussion}

\section{Environmental values, beliefs, and knowledge}

The revised NEP scale is widely used and has been extensively validated as an accurate measure of environmental values. In 


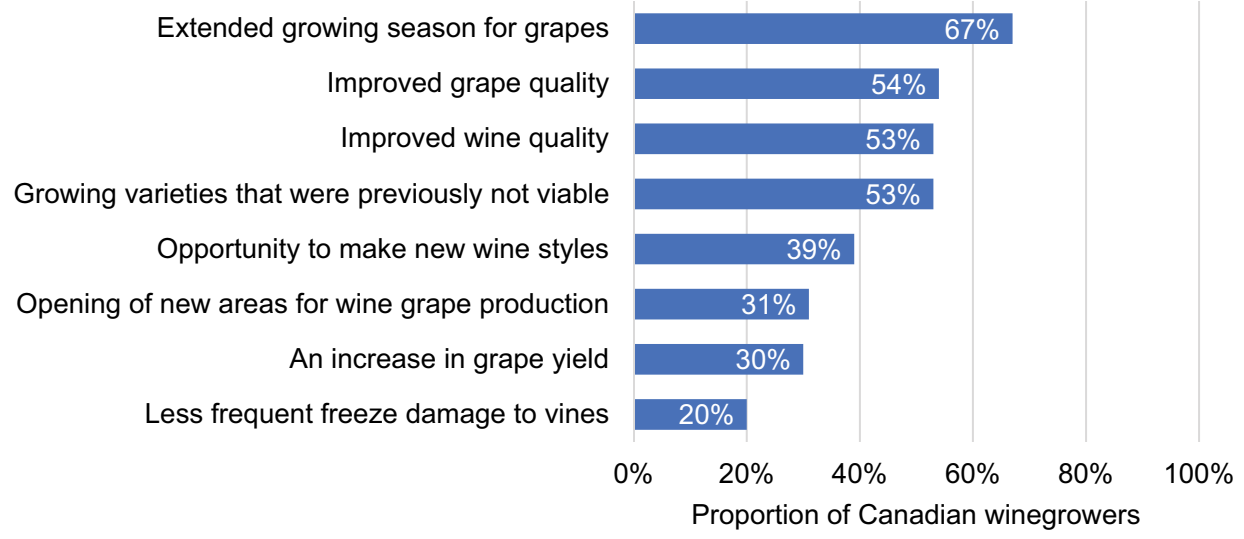

Figure 2 Perceived benefits of climate change for the wine industry.

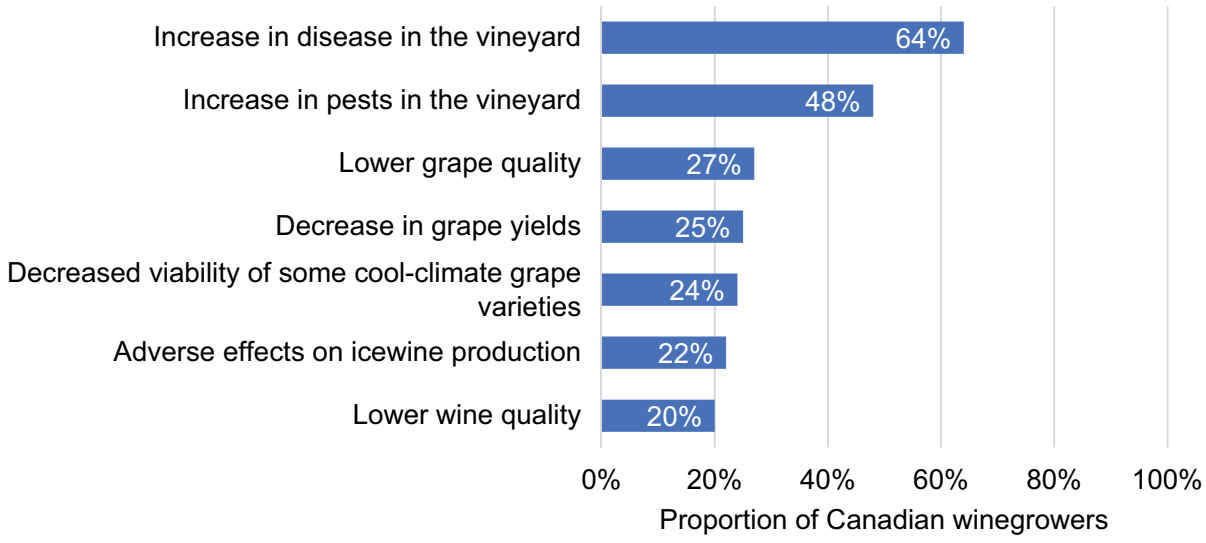

Figure 3 Perceived disadvantages of climate change for the wine industry.

several previous studies, an ecological worldview - represented by a high NEP score - has been associated with pro-environmental intentions and behaviors. Conversely, an anti-ecological worldview - represented by a low NEP score - has been associated with low ecological support and actions. ${ }^{12-14}$ Much like the general Canadian population, ${ }^{36,42}$ winegrowers appear to have a more ecocentric than anthropogenic worldview. Furthermore, there was no significance difference in average NEP scores between provinces, ownership status, and roles in the winery. Therefore, the results suggest that Canadian winegrowers may be inclined to support and act in favor of the environment.

The average winegrower's score for $\mathrm{CC}$ uncertainty and skepticism is relatively low. More specifically, most respondents seem to have a low level of uncertainty regarding the existence of $\mathrm{CC}$, but their uncertainty with regards to the effects of CC is mixed. A multitude of reasons could explain this trend, but perhaps one of the main factors is the uncertain nature of $\mathrm{CC}$ itself. As a complex phenomenon,
$\mathrm{CC}$ abounds with uncertainty. ${ }^{43}$ In fact, understanding the impacts of CC not only requires a high level of scientific literacy but also involves the mental process of transposing predicted changes into natural and human systems to fully appreciate the concrete implications for humans' daily lives. It also requires people's attention to and trust in the media providing $\mathrm{CC}$ information which, in turn, can convey conflicting messages ${ }^{43,44}$ All those factors combined can exacerbate the level of uncertainty about the effects of CC. Additionally, winegrowers arguably experience and are attentive to numerous climate variations, which can impact their production. In this context, determining which specific effect is attributable to $\mathrm{CC}$ rather than to normal climate variability could be arduous and could, thereby, reinforce uncertainty. The results also show that only a minority of participants believe that the seriousness of CC is exaggerated and that the media is too alarmist about CC. Those results are similar to those reported by Morris and Pickering ${ }^{36}$ for a representative sample of the 
adult Canadian population and suggest that Canadian winegrowers understand the seriousness of the issue.

Respondents who identified as grape-growers trended toward a higher skepticism score than respondents who identified as both grape-growers and winemakers. This difference could be due to the more diverse experience of individuals who are responsible for grape growing as well as winemaking. Indeed, while grape-growers mostly witness the repercussions of climate variabilities in the vineyard, winemakers observe the effects in the grape must and the processed wine. The coupled experiences might reinforce the perception that $\mathrm{CC}$ is not only happening but also serious, and its effects are evident; this, in turn, could decrease uncertainty and skepticism.

Our findings also show that almost all Canadian winegrowers $(97 \%)$ recognize the effect of human activities on $\mathrm{CC}$; this suggests that the prevalence of attribution skepticism is very low among winegrowers, similar to the general Canadian population. ${ }^{36}$ This is also consistent with prior studies that have indicated that only a small part of the population completely rejects the notion of anthropogenic CC. ${ }^{10,11}$ However, this small group of people tend to be more vocal about their opinions than people who acknowledge the veracity of the issue ${ }^{11}$ and may receive a disproportionate amount of attention from the media. In turn, this could perpetuate the misconception that they form a significant part of the population, ${ }^{18}$ which may extend to how the CWI is perceived and represented on the issue of $\mathrm{CC}$.

Knowledge of $\mathrm{CC}$ is a necessary precursor for $\mathrm{CC}$ perceptions and can be either a barrier or a motivator to actions. ${ }^{11,16}$ Using Stoutenborough and Vedlitz's ${ }^{16}$ index, we determined that winegrowers have an average assessed knowledge score of $55.3 \%$, which is significantly lower than that of experts (100\%). This suggests that Canadian winegrowers may be less likely than experts to perceive $\mathrm{CC}$ risks, which might diminish their likelihood of appropriately understanding and addressing them. Furthermore, the results show that the level of assessed knowledge is independent from winegrowers' professional roles in the winery, their ownership status, and their provinces of work, suggesting that there is an opportunity for further CC knowledge transfer throughout the CWI.

Despite its popularity, the measure of self-assessed or perceived CC knowledge has been criticized in the past because it can be erroneous and shows little support for the Knowledge Deficit Model. ${ }^{16,45}$ Nevertheless, measuring perceived $\mathrm{CC}$ knowledge has value since it illustrates the extent to which people think they know an issue, which might inform their disposition and interest in increasing their $\mathrm{CC}$ literacy. Out results show that Canadian winegrowers have a higher level of perceived CC knowledge (6.6) than the general Canadian population (5.8), as assessed by Morris and Pickering. ${ }^{36}$ This could be partly due to the nature of winegrowers' work, which is intrinsically linked to the environment and climate variabilities, thereby making them more likely than the rest of the population to know - or think they know - more about CC. Also, on average, winegrowers perceived their knowledge to be higher that their assessed CC knowledge. While the gap between scientific and perceived knowledge is modest (between $2 \%$ and $13 \%$ ), it indicates a broad trend: Canadian winegrowers are prone to overestimate their $\mathrm{CC}$ knowledge. An overestimation of knowledge may lead to a lack of interest in learning more about CC. ${ }^{16}$ Consequently, while the results show that there is room for improvement in terms of scientific knowledge, winegrowers might not be as willing to use their resources to learn more about CC if they perceive that they already know enough about it.

\section{Perceived positive and negative consequences of climate change}

CC could provide opportunities for and cause damage to the CWI ${ }^{24,27}$ Much like the winegrowers of Ontario, ${ }^{27}$ Italy, France, and Germany, ${ }^{34}$ our results suggest that most Canadian winegrowers (92\%) are aware that $\mathrm{CC}$ has consequences on their operations. Among the respondents who acknowledge the consequences of $\mathrm{CC}$, a majority (60\%) perceive them as both positive and negative, while the remainder perceive $\mathrm{CC}$ consequences as being either mostly positive $(16 \%)$ or mostly negative $(16 \%)$.

In this study, extended growing season for grapes was the most selected positive consequence of $\mathrm{CC}$ for vineyards and winery operations. This result is unsurprising, given that the potential for the industry to extend further into the vast northern regions of the country is largely limited by the inability of grapes to ripen there in the relatively short growing season..$^{23}$ In addition, our findings show that Canadian winegrowers are more likely to perceive $\mathrm{CC}$ as being favorable than detrimental for the quality of grapes and wines. As observed by Battaglini et al, ${ }^{34}$ who reported similar results among European winegrowers, this is due to the understanding among winegrowers that warmer temperatures and possibly, more sunny days - are associated with higher grape and wine quality. ${ }^{34}$ In cool-climate and marginal grape-growing regions, this perspective can understandably seem promising for winegrowing, despite the potentially negative impacts of warmer temperatures outlined earlier.

On the other hand, the most frequently selected negative impact of $\mathrm{CC}$ is the increase in disease in the vineyards, 
followed by an increase in pests in the vineyards. Since these two consequences can potentially affect grapes and wine quantity and quality, ${ }^{23,24,27}$ it is surprising that lower grape quality, decrease in grape yields, and lower wine quality were only selected by less than a third of participants. This could indicate that winegrowers are confident in their capacity to handle more disease and pest pressure without compromising their production.

More than half of respondents selected the opportunity to grow varieties that were previously not viable as being a positive consequence of $\mathrm{CC}$ while, conversely, less than a third of them selected the decreased viability of some coolclimate grape varieties and the adverse effects on icewine production. This insinuates that winegrowers may think that $\mathrm{CC}$ will provide more opportunities than loss regarding the size and variety of their wine portfolio. Again, those perceptions might be, in part, attributable to the common belief that cold temperatures are the primary deterrent to quality grape growing and winemaking. Indeed, while some cool-climate grape varieties such as Riesling typically do well in Canada, winegrowers must often cope with the consequences of freeze damage and, consequently, may believe that the benefits of warmer temperatures outweigh the potential disadvantages associated with it, for instance, a shorter window for icewine harvest. The industry currently relies heavily on icewine exports for its economic viability; indeed, Canada is the world's largest icewine producer per volume, and this product accounts for almost a quarter of its wine exportation. ${ }^{20}$ Therefore, underestimating the impact of $\mathrm{CC}$ on icewine production could be risky for the sustainability of the CWI.

\section{Limitations and further research}

The main limitation of this study is the relatively small sample size. While most Canadian winegrowers' associations and wineries were contacted, a rather small percentage of the winemakers, grape-growers, and owners completed the survey. This could be due to many factors, including the length of the survey. Also, participation bias may be a noteworthy limitation. Specifically, the topic of the study might have attracted more "environmentally conscious" winegrowers, and as a result, the responses may not be as reflective of the whole industry as desired.

The success of the CWI relies on its ability to continuously produce quality wine and to be competitive in an aggressive international market. In the context of $\mathrm{CC}$, the need to understand and appropriately respond to the present and future climate alterations is imperative. Hence, future research should take into account the importance of winegrowers' opinions and perceptions of $\mathrm{CC}$, which is reflective of their needs and, most likely, their willingness to embrace new technologies and methods. Also, determining the current state of CC adaptation in the CWI could provide an important benchmark, illuminate weaknesses, and help inform new policies and potential contributions from the various actors of the industry. Barriers other than perceptions, including financial resources and the availability of the required technologies to adjust existing operations, should also be part of the discussion around $\mathrm{CC}$ impacts and adaptation in the CWI.

\section{Conclusion}

This is the first study to characterize Canadian winegrowers' environmental values, $\mathrm{CC}$ knowledge and beliefs, and perceptions of the consequences of $\mathrm{CC}$ on the wine industry. Canadian winegrowers generally have a pro-environmental worldview, are moderately knowledgeable about $\mathrm{CC}$, and have a low level of skepticism regarding the existence and seriousness of the phenomenon. Furthermore, they largely acknowledge that $\mathrm{CC}$ has positive as well as negative consequences for their industry. However, they are somewhat uncertain about the specific effects of $\mathrm{CC}$ in general and on their operations. Overall, our findings indicate the need to document and explain the effects of $\mathrm{CC}$, rather than to reinforce the veracity of its existence and the anthropogenic contribution to its aggravation within the winegrower and grape-grower population in Canada. Indeed, the uncertainty of the consequences of $\mathrm{CC}$ can obstruct the development and implementation of effective adaptations strategies, which are much needed for the CWI. Moreover, uncertainty can restrain people from supporting climate policies, since their benefits are not well understood or are not perceived as valuable. Therefore, an effective knowledge transfer and collaboration strategy involving all the relevant stakeholders of the industry - but especially between winegrowers and CC experts - are indicated to improve the capacity of the industry to develop and adjust to the consequences of $\mathrm{CC}$.

\section{Acknowledgments}

The contribution of the winegrowers who took part in the survey is gratefully acknowledged. Thank you to the Social Science and Humanities Research Council of Canada, the Brock University Faculty of Graduate Studies, and the Environmental Sustainability Research Center for their financial support of this project. Winegrowers' associations of Ontario, British Columbia, Québec, and Nova Scotia, as well as Sarah Moore, Steven Trussler, Marc Pistor, Jamie Quai, and Jérémie d'Hauteville are sincerely thanked for their assistance with recruitment. Hannah Pickering is thanked for her valuable assistance with the survey design. 


\section{Disclosure}

The authors report no conflict of interest in this work.

\section{References}

1. Intergovernmental Panel on Climate Change [homepage on the internet]. Climate change 2014: synthesis report. Contribution of Working Group I, II and III to the Fifth Assessment Report of the Intergovernmental Panel on Climate Change [2015]. Available from: https://www.ipcc. $\mathrm{ch} / \mathrm{pdf} /$ assessment-report/ar5/syr/SYR_AR5_FINAL_full_wcover.pdf. Accessed May 5, 2017.

2. Jones GV, Webb LB. Climate change, viticulture, and wine: challenges and opportunities. J Wine Res. 2010;21(2-3):103-106.

3. Mozell MR, Thach L. The impact of climate change on the global wine industry: challenges \& solutions. Wine Econ Policy. 2014;3(2):81-89.

4. Ollat N, de Cortazar-Atauri IG, Touzard JM. The challenging issue of climate change for a sustainable grape and wine production. Book of Proceeding of the Climwine International Symposium, Bordeaux, France, April 10-13, 2016. Bordeaux, Paris; Vigne \& Vin Publications Internationales: 2016.

5. The Detroit News [homepage on the internet]. Lavenworth S. Winemakers warming to reality of climate change [November 3, 2017]. Available from: https://www.detroitnews.com/story/business/2017/11/03/ winemakers-climate-change/107312574/. Accessed May 18, 2018.

6. The Harvard Gazette [homepage on the internet]. Ruell P. To adapt to warmer temperatures, vintners may have to plant lesser-known varieties [January 9, 2018]. Available from: https://news.harvard.edu/gazette/ story/2018/01/as-climate-changes-so-does-wine/. Accessed May 11, 2018.

7. Hirsch Hadorn G, Hoffmann-Riem H, Biber-Klemm S. Handbook of Transdisciplinary Research. Dordrecht, the Netherlands: Springer; 2008.

8. Capstick S, Whitmarsh L, Poortinga W, Pidgeon N, Upham P. International trends in public perceptions of climate change over the past quarter century. Wiley Interdiscip Rev Clim Change. 2015;6(1): $35-61$.

9. Bennett NJ. Using perceptions as evidence to improve conservation and environmental management. Conserv Biol. 2016;30(3):582-592.

10. Whitmarsh L. Scepticism and uncertainty about climate change: dimensions, determinants and change over time. Global Environ Change. 2011;21(2):690-700.

11. Gifford R. The dragons of inaction: psychological barriers that limit climate change mitigation and adaptation. Am Psychol. 2011;66(4):290-302.

12. Dunlap RE, Van Liere KD, Mertig AG, Jones RE. New trends in measuring environmental attitudes: measuring endorsement of the new ecological paradigm: a revised NEP scale. J Soc Issues. 2000;56(3):425-442.

13. Whitmarsh L. Are flood victims more concerned about climate change than other people? The role of direct experience in risk perception and behavioural response. J Risk Res. 2008;11(3):351-374.

14. Ziegler A. Political orientation, environmental values, and climate change beliefs and attitudes: an empirical cross country analysis. Energy Econ. 2017;63:144-153.

15. Simis MJ, Madden H, Cacciatore MA, Yeo SK. The lure of rationality: why does the deficit model persist in science communication? Public Underst Sci. 2016;25(4):400-414.

16. Stoutenborough JW, Vedlitz A. The effect of perceived and assessed knowledge of climate change on public policy concerns: an empirical comparison. Environ Sci Policy. 2014;37:23-33.

17. Hornsey MJ, Harris EA, Bain PG, Fielding KS. Meta-analyses of the determinants and outcomes of belief in climate change. Nat Clim Chang. 2016;6(6):622-626.

18. Potsdam Institute for Climate Impact Research [homepage on the internet]. Rahmstorf, S. The climate sceptics [2004]. Available from: https://www.pik-potsdam.de/news/public-events/archiv/alter-net/ former-ss/2006/programme/28-08.2006/rahmstorf/literature/rahmstorf_ climate_sceptics_2004.pdf/view?searchterm=rahmstorf. Accessed May 17, 2018.
19. Intergovernmental Panel on Climate Change. Climate Change 2001: Mitigation. Contribution, Contribution of Working Group I, II and III to the Fifth Assessment Report of the Intergovernmental Panel on Climate Change. Cambridge, UK; Cambridge University Press; 2001.

20. Canadian Vintners Association [homepage on the internet]. Canadian wine and grape industry contributed $\$ 9$ billion to Canadian economy; 2017. Available from: http://www.canadianvintners.com/economicimpact/. Accessed March 18, 2018.

21. Radio Canada International [homepage on the internet]. Montgomery M. Canadian wine wins world's best! [October 4, 2013]. Available from: http://www.rcinet.ca/en/2013/10/04/canadian-wine-wins-worlds-best/. Accessed May 18, 2018.

22. Statistics Canada [homepage on the internet]. From the vine to the glass: Canada's grape and wine industry [updated 2009 November 12]. Available from: https://www150.statcan.gc.ca/n1/pub/11-621-m/11621-m2006049-eng.htm. Accessed May 18, 2018.

23. Reynolds AG. Managing Wine Quality, Volume 1: Viticulture and Wine Quality. Cambridge, UK: Woodhead Publishing in Food Science, Technology and Nutrition; 2010.

24. Shaw TB. Climate change and the evolution of the Ontario cool climate wine regions in Canada. J Wine Res. 2016;0(0):1-33.

25. Jones NK. The influence of recent climate change on wine regions in Quebec, Canada. J Wine Res. 2012;23(2):103-113.

26. Roy $P$, Grenier P, Barriault E, et al. Probabilistic climate change scenarios for viticultural potential in Québec. Clim Change. 2017;143(1-2):43-58.

27. Pickering K, Plummer R, Shaw T, Pickering G. Assessing the adaptive capacity of the Ontario wine industry for climate change adaptation. Int $J$ Wine Res. 2015;7(1):13-27.

28. Cyr D, Shaw AB. Impact of global warming on Ontario's Icewine industry. Proceedings of the VIII International Terroir Congress, Soave, Italy, June 14-18, 2010. Soave, Italy: The VIII International Terroir Congress (online); 2010.

29. Intergovernmental Panel on Climate Change [homepage on the internet]. Managing the risks of extreme events and disasters to advance climate change adaptation. A special report of working groups I and II of the Intergovernmental Panel on Climate Change [2012]. Available from: https://www.ipcc.ch/pdf/special-reports/srex/SREX_Full_Report.pdf . Accessed April 13, 2018.

30. Natural Resources Canada [homepage on the internet]. Overview of climate change in Canada [2015 November 10]. Available from: https://www.nrcan.gc.ca/environment/resources/publications/impactsadaptation/reports/assessments/2008/ch2/10321. Accessed May 11, 2018.

31. Jackson DI, Lombard PB, Kabinett LQ. Environmental and management practices affecting grape composition and wine quality - a review. $\mathrm{Am}$ J Enol Vitic. 1993;44(4):409-430.

32. Mullins MG, Bouquet A, Williams LE. Biology of the Grapevine. Cambridge, UK: Cambridge University Press; 1992.

33. Duarte Alonso A, O'Neill MA, Alonso A, O'Neill M. Climate change from the perspective of Spanish wine growers: a three-region study. $\mathrm{Br}$ Food J. 2011;113(2):205-221.

34. Battaglini A, Barbeau G, Bindi M, Badeck F-W. European winegrowers' perceptions of climate change impact and options for adaptation. Reg Environ Change. 2009;9(2):61-73.

35. Spence A, Poortinga W, Pidgeon N. The psychological distance of climate change. Risk Anal. 2012;32(6):957-972.

36. Morris S, Pickering GJ. Visual representations of climate change in Canada. Can. J. Comm. (in review). 2019.

37. Liu X, Stoutenborough J, Vedlitz A. Bureaucratic expertise, overconfidence, and policy choice. Governance. 2017;30(4):705-725.

38. Heinricks G. Starting a Vineyard in Prince Edward County? A Viticultural Primer for Investors and Growers. Cornell University, Ithaca, New York; 2001.

39. Holland T, Smit B. Climate change and the wine industry: current research themes and new directions. JWine Res. 2010;21(2-3):125-136.

40. Jones GV, White MA, Cooper OR, Storchmann K. Climate change and global wine quality. Clim Change. 2005;73(3):319-343. 
41. Ogunbode CA. The NEP scale: measuring ecological attitudes/ worldviews in an African context. Environ, Dev Sustain. 2013;15(6): 1477-1494.

42. Pickering GJ. Head in the (oil) sand ? Climate change scepticism in Canada. J Environ Soc Sci. 2015;2(2):1-11.

43. Weber EU. What shapes perceptions of climate change? Wiley Interdiscip Rev Clim Change. 2010;1(3):332-342.
44. Braman D, Kahan DM, Peters E, Wittlin M, Slovic P. The polarizing impact of science literacy and numeracy on perceived climate change risks. Nat Clim Chang. 2012;2(10):732-735.

45. Kellstedt PM, Zahran S, Vedlitz A. Personal efficacy, the information environment, and attitudes toward global warming and climate change in the United States. Risk Anal. 2008;28(1):113-126.
International Journal of Wine Research

\section{Publish your work in this journal}

The International Journal of Wine Research is an international, peer-reviewed open-access journal that focuses on all scientific aspects of wine, including: vine growing; wine elaboration; human interaction with wine; health aspects of wine. The journal provides an open access platform for the reporting

\section{Dovepress}

of evidence based studies on these topics. The manuscript management system is completely online and includes a very quick and fair peer-review system, which is all easy to use. Visit http://www.dovepress.com/testimonials.php to read real quotes from published authors.

Submit your manuscript here: https://www.dovepress.com/international-journal-of-wine-research-journal 